\section{B A Institute of \\ YK Business Administration \\ 六下 \\ Karachi \\ Leadership and Ideas for Tomorrow}

Business Review

Volume 12 Issue 2 July - December 2017

7-1-2017

\title{
Measuring the knowledge creation process in Pakistani banks: Scale development and validation
}

\author{
Salman Bashir Memon \\ Shah Abdul Latif University, Khairpur \\ Wajid Hussain \\ Institute of Business Administration, Karachi, Pakistan \\ Huma Amir \\ Institute of Business Administration, Karachi, Pakistan
}

Follow this and additional works at: https://ir.iba.edu.pk/businessreview

\section{(c) (9)}

This work is licensed under a Creative Commons Attribution 4.0 International License.

\section{Recommended Citation}

Memon, S. B., Hussain, W., \& Amir, H. (2017). Measuring the knowledge creation process in Pakistani banks: Scale development and validation. Business Review, 12(2), 1-21. Retrieved from https://doi.org/ 10.54784/1990-6587.1040

This article is brought to you by iRepository for open access under the Creative Commons Attribution 4.0 License and is available at https://ir.iba.edu.pk/businessreview/vol12/iss2/1. For more information, please contact irepository@iba.edu.pk. 
Business Review: (2017) 12(2):1-21

Original Paper

\title{
Measuring the knowledge creation process in Pakistani banks: Scale development and validation
}

\author{
Salman Bashir Memon • Wajid Hussain \\ Rizvi - Huma Amir
}

\begin{abstract}
Knowledge creation within an organization arises from socialization, externalization, combination and internalization of knowledge resources. This paper contributes to the body of knowledge management literature by providing an empirical validation of the knowledge creation process in the context of Pakistani banks. A sample of 346 cases was selected randomly from 50 branches of three knowledge-intensive banks in Karachi. The results confirm the presence of knowledge creation in Pakistani banks and the validation process of the scale was used to measure this. Our findings can help managers develop successful knowledge creation and sharing strategies that utilize tacit and explicit knowledge resources more effectively.
\end{abstract}

Keywords Knowledge creation process - Confirmatory factor analysis · Reliability $\cdot$ Convergent validity $\cdot$ Knowledge-intensive bank.

\section{Introduction}

Over the past two decades, knowledge management (KM) has emerged as a separate field of management science research Kao et al (2011) Rai (2011) Nonaka and Konno (1998). In a knowledge economy, knowledge is the fundamental resource for companies that can form the basis of sustainable competitive advantage. Thus, an appropriate understanding of how to make optimal use of knowledge management strategies is crucial Shih et al (2010).

Existing global business activities are becoming more knowledge-intensive as knowledge is becoming the source of productivity within and across economies.

Salman Bashir Memon

Shah Abdul Latif University, Khairpur

Wajid Hussain Rizvi

Institute of Business Administration, University Road, Karachi-Pakistan

E-mail: wrizvi@iba.edu.pk

Huma Amir

Institute of Business Administration, University Road, Karachi-Pakistan 
However, the inability to effectively apply knowledge in the manufacturing and production processes is accelerating the economic divide between developed and developing countries Akhtar (2001) Jamal and Naser (2003).

Pakistani public and private sector organizations lack appropriate knowledge management strategies that can improve their competitive positioning in national and international markets Khilji (2003). The advent of globalization has brought striking changes to workplace values which reflect a modern market economy Khilji (2004). Pakistani organizations experience a variety of structural and institutional irregularities that diminish their capabilities to take advantage of the dynamic business environment Bhatti and Qureshi (2007). In 1990, a privatization program was initiated to break free off the bureaucratic culture and restructure human resource practices Mirza (1995). The intent was to introduce modern management practices, reduce nepotism and red tape Khilji (2003).

Keeping in view the importance of knowledge management, the fundamental aim of the underlying empirical study is to validate a knowledge creation process theory in Pakistani banks. This study is the first attempt to measure and validate the 'knowledge creation process' scale in Pakistani organizations (i.e. banks).

\section{Theoretical perspective of knowledge creation}

Early identification of the knowledge creation (KC) phenomenon by Nonaka (1994)( p.5) noted that "successful companies are those that constantly create new knowledge, distribute it throughout the organization and embody it in new technologies and products". Nonaka et al (2001) define knowledge creation as "a continuous process through which one overcomes the individual limitations and restrictions imposed by prevailing information and experience by attaining a new perspective, a new observation of the environment and new knowledge Nonaka et al (2000) (p.7)". In addition, the spiral of knowledge is created when both tacit and explicit knowledge is complementing and interfacing each other through four switching modes namely; socialization, externalization, combination and internalization. Hence, knowledge creation is a process in which personal knowledge is continuously validated by integrating someone else's knowledge through the four modes of the knowledge conversion spiral Nonaka et al (2000).

Socialization (tacit $\rightarrow$ tacit): The first knowledge conversion mode socialisation is the "process of sharing experiences through social interaction thus creating tacit knowledge, such as shared mental models and technical skills". Nonaka and Takeuchi (1995)(p.62). In this phase of the knowledge conversion process, existing tacit knowledge is transformed to create a new type of tacit knowledge Nonaka et al (2000) Byosiere and Luethge (2004) Nonaka and Takeuchi (1995).

Externalization (tacit $\rightarrow$ explicit): The second knowledge conversion mode typically seen in terms of concept creation is activated by conversation or collective reflection Nonaka and Takeuchi (1995). In this knowledge conversion mode, tacit (i.e. subjective, intangible, inexpressible) knowledge is converted into explicit (i.e. objective, tangible, expressible) knowledge. Knowledge exter- 
nalization can be attained when people get help from technical terminologies and professional language in routine communications with each other in the organization.

Combination (explicit $\rightarrow$ explicit): The third knowledge conversion mode is the process in which existing explicit knowledge is collected from knowledge repositories or databases and transformed into more customized, assimilated, remodeled and reconfigured explicit knowledge Nonaka et al (2000) Byosiere and Luethge (2004) Nonaka and Takeuchi (1995). In the combination phase, people can exchange and combine knowledge in tangible or intangible forms, collect new information and organize ambiguous concepts into structured form.

Internalization (explicit $\rightarrow$ tacit): The fourth knowledge conversion mode is the last sequential stage in which tacit knowledge is created through the process of reviewing and interpreting explicit knowledge and converting it into tacit knowledge Nonaka et al (2000). More specifically, the internalization process involves learning by doing. It strengthens the learner's confidence and knowledge and the skills become entrenched in an individual's mind and can be deployed in specific contexts Haag et al (2009).

\section{Knowledge creation measurement}

The SECI process of the knowledge creation theory is based on four modes. It provides a distinctive framework that broadly covers the knowledge sharing and creation process Earl (2001) Von Krogh et al (2000) Haag et al (2009). Therefore, the SECI model is used for item specification in the context of knowledgeintensive banking organizations Hinkin (2005) Song et al (2011). The socialization and internalization modes facilitate human-oriented KM, while externalization and combination support technology-oriented KM Maier and Remus (2003).

Socialization and internalization processes can be triggered by face to face conversations, on the job-training, mentoring, coaching, community of practice, teamwork, employee empowerment, and reward and recognition Vencatachellum and Jeetah (2008). Knowledge externalization and combination processes on the other hand are associated with information systems and technology in which tacit knowledge is converted into explicit knowledge by updating and integrating business processes and I.T platforms Maier and Remus (2003).

The knowledge creation scale developed by Song et al (2011) provides an appropriate and effective measurement scale for the knowledge creation process. For empirical validation of the knowledge creation theory, a twenty-four item scale has been adapted from Song et al (2011). In other words, the selected scale provides a solid ground that embraces the knowledge creation process and the core behaviors deemed essential for exploring and exploiting organizational knowledge creation at tactical, operational, and technical levels Song et al (2011).

For the final selection of the knowledge creation scale, a detailed literature review was carried out. The researcher thoroughly assessed previous established scales (table 1) published during the period 2002 till 2011. Only those knowl- 
edge creation scales were considered that had been developed deductively and in which Nonaka's SECI knowledge creation theory was taken for item specification.

Table 1: Established scales on knowledge creation

\begin{tabular}{|c|c|c|}
\hline Author (Year) & Domain & Knowledge Modes \\
\hline Huang \& Wang (2002) & $\begin{array}{l}\text { Knowledge creation and } \\
\text { performance in teams }\end{array}$ & $\begin{array}{l}\text { Team innovation ef- } \\
\text { fectiveness, knowledge } \\
\text { transfer, knowledge } \\
\text { creation, R\&D perfor- } \\
\text { mance }\end{array}$ \\
\hline Chou \& Tsai (2004) & $\begin{array}{l}\text { Individual and organi- } \\
\text { sational knowledge }\end{array}$ & Knowledge creation 'ba' \\
\hline Tsai \& Li (2007) & $\begin{array}{l}\text { Knowledge creation } \\
\text { process }\end{array}$ & $\begin{array}{l}\text { Socialisation, external- } \\
\text { isation, combination, } \\
\text { and internalisation }\end{array}$ \\
\hline Li et al. (2009) & $\begin{array}{l}\text { Knowledge creation } \\
\text { process }\end{array}$ & $\begin{array}{l}\text { Socialisation, external- } \\
\text { isation, combination, } \\
\text { and internalization }\end{array}$ \\
\hline Song et al. (2011) & $\begin{array}{l}\text { Knowledge creation and } \\
\text { performance improve- } \\
\text { ment }\end{array}$ & $\begin{array}{l}\text { Socialisation, external- } \\
\text { isation, combination, } \\
\text { and internalization }\end{array}$ \\
\hline Kao et al. (2011) & $\begin{array}{l}\text { Knowledge creation } \\
\text { modes }\end{array}$ & $\begin{array}{l}\text { Goal free and goal- } \\
\text { framed knowledge cre- } \\
\text { ation modes }\end{array}$ \\
\hline
\end{tabular}

\subsection{Quantitative survey method}

The sample was randomly selected from 50 branches of Habib Bank Limited (HBL), United Bank Limited (UBL) and Allied Bank Limited (ABL), in Karachi. The contact details of bank employees were officially obtained from human resource managers of each bank. The contact details were used as a sampling frame for quantitative data collection by one of the two ways. Firstly, the researcher sent the HTML-generated link to 350 respondents on their email addresses with a formal request to complete the online survey. Secondly, a paperbased self-administered survey was randomly distributed among 250 respondents in their offices during field work, in Karachi.

The paper-based self-administered survey focused on tellers/junior officers, branch/operation managers, regional/senior managers, and clerical/non-clerical staff of various job categories such as, retail, consumer, investment, corporate, and investment banking etc. In both versions of the survey, a total of 600 questionnaires were distributed to the three commercial banks, in Karachi. As a 
Table 2: Comparative framework of EFA and CFA Albright and Park (2009)

\begin{tabular}{lll}
\hline Parameter & EFA & CFA \\
\hline Scope & Data-driven & Theory-driven \\
Constraint & Not related & Yes \\
Un-standardised solution & Not related & Yes \\
Standardised solution & Yes & Yes \\
Factor rotation & Yes & Not related \\
Factor scores & Yes & Not related \\
Hypothesis test & Not related & Yes \\
Good of fit & Not related & Yes \\
Software Package & Gen purpose software & EQS,LISREL,MPLUS,AMOS \\
\hline
\end{tabular}

result, a sum of 346 (i.e. 143 electronic +203 paper $=346$ ) questionnaires were returned. The total response rate was $40.85 \%$ (i.e. $143 / 350 * 100=40.85 \%$ ) for the electronic survey and $81.2 \%$ (i.e. $203 / 250 * 100=81.2 \%$ ) for the paper survey. The combined survey generated $57.6 \%$ (i.e. $346 / 600 * 100=57.6 \%$ ) usable response rate.

\subsection{Scale validation framework}

Scale validation is an important aspect of any research. Empirically, it is difficult to ensure the soundness of research without determining the reliability and validity of the scale Sureshchandar et al (2002). Generally, if any scale has never been tested before, or the relationship between observed and latent variables has not been theoretically established then an exploratory factor analysis is the only choice Ahire and Devaraj (2001).

Exploratory factor analysis (EFA) is a data-driven approach in which each common factor is assumed to affect every observed variable and the common factors are either correlated or uncorrelated Brown (2014). Once the model is estimated then the factor scores and proxies of latent variables are calculated and used for follow-up analysis Albright and Park (2009).

In contrast, confirmatory factor analysis (CFA) is theory or hypothesisdriven. The CFA allows researchers to test the hypotheses about a particular factor structure. In addition, confirmatory factor analysis (CFA) is a comprehensive statistical technique that determines the validity of theoretical structures through testing the causal links among variables Anderson and Gerbing (1991) Burnette and Williams (2005) Kline (2015). Table 2 summarizes the differences and similarities of EFA and CFA.

In CFA, the researchers are required to devise a hypothesis as it allows the researcher to specify a model on the basis of logic or priori. For that reason, researchers first devise some hypothetical model and then test the inference that corroborates the relationship between observed and the latent variables Sureshchandar et al (2002). Hence, a reasonable prior knowledge of factors that clarify the interrelationship among the measured variables is an integral part of 
CFA.

CFA is more suitable than EFA because it builds on logic, particularly when a researcher has a reasonably good prior knowledge about observed variables and other theoretical findings Bentler (1995). It is a matter of fact that knowledge creation models are theoretically established. Therefore, CFA has been utilized for the purpose of scale refinement and validation.

A typical structural equation model consists of two components: a) measurement model; and b) structural model. CFA is a measurement model. It illustrates the relationships between a set of observed (or dependent) variables and a set of continuous, latent variables. In this study, a confirmatory factor analysis (CFA) model with a first-order factor structure (or continuous factor indicators) and a second-order factor analysis models are estimated. More specifically, the first-order CFA was used to assess the structural validity, reliability and dimensionality of the scale whereas the second-order CFA was used to assess the model fit of hypothesized second-order factors Jöreskog and Sörbom (1996) Yang (2005).

According to Byrne (2003), the second-order CFA is potentially applicable when the first-order CFA signifies a higher inter-correlation among the factors. In the following section, the first and second-order confirmatory factor analysis of the knowledge creation scale has been explained. However, for scale refinement and validation, the researcher followed the instructions of Sureshchandar et al (2002).

\subsection{Reliability and validity analysis}

Reliability and validity measurement is an important tool that increases research credibility and diminishes the likelihood of fabricated results Winter (2000). The following section summarises several measures of reliability and validity used in this study.

The reliability of the scale was measured in two phases. First, in the pilot study phase and second, after conducting confirmatory factor analysis. Numerically, reliability can be measured by various methods such as, split halve, test reset, internal consistency and equivalent form. In the pilot study phase of this research, reliability of the scale was measured using an internal consistency method. Sureshchandar et al (2002) and Nunnally (2010) found internal consistency as an effective and commonly used technique. However, measuring construct reliability (CR) after CFA was used to assess the reliability of the manifest indicators, and provide an alternative for determining measurement model fit.

The term validity refers to the methodological soundness and the appropriateness of the instrument Hashim et al (2007). In other words, validity is the degree to which the results of a piece of research exactly reflect the situation being researched. Like reliability, the validity of the scale has been established in both the pilot and post-hoc scale development phases. In the pilot testing phase, face and content validity were measured. In the post-hoc scale valida- 
tion phase, convergent validity and discriminate validity were measured using confirmatory factor analysis approach. The subsequent section summarises the detail of both reliability and validity techniques used in this study.

\subsubsection{Reliability of the scale in the pilot study phase}

The online survey during the pilot study was initiated in May 2012 and completed in July 2012. The researcher sent the HTML link of the electronic survey to 75 bank employees from the target population of the banking industry, on a convenience basis. A total of 29 respondents completed the online survey. The response rate of this phase remained $38.6 \%$ (i.e. $29 / 75 * 100=38.6 \%$ ).

These 29 responses were utilized to measure the internal consistency or coefficient alpha $(\alpha)$ values of the 28 items and composite reliability of 04 dimensions. The coefficient alpha $(\alpha)$ values of each index $(\alpha=0.849, \alpha=0.865, \alpha=0.802$ and $\alpha=0.749)$ and the composite reliability of knowledge creation $(\alpha=0.884)$ were higher than the suggested minimum threshold limit of 0.60 Bagozzi and Yi (1988). This result indicates an acceptable evidence of the scale's internal consistency and strong interrelationship between 28 items and 4 knowledge creation dimensions Hatcher (2005).

\subsubsection{Validity of the scale in the pilot study phase}

Unlike other scientific methods, face validity is least scientific method of measuring validity. It focuses on subjective judgment and does not make use of statistical methods. More specifically, the purpose of such type of measurement is to examine how the survey appears to be valid for respondents and whether or not subjective judgment can be made by the researcher.

Face validity was measured by sending the questionnaire to $50 \mathrm{PhD}$ students of four U.K universities (Queen Margaret, Swansea, Northumbria and London Metropolitan) and two universities (SALU and SZABIST) in Pakistan. The underlying objective of this phase was to inspect language issues and face validation of the questionnaire and to ensure that whether the participants understand the survey questions and if any further amendments are required in the survey. All the responses were checked precisely, and each item was reviewed for the use of familiar words. In addition, respondents were also asked for their feedback and all suggestions were vigilantly incorporated in the final version of the survey.

Content validity refers to the extent to which an instrument provides an adequate demonstration of the conceptual underpinning that it is intended to cover. Like face validity, content validity also provides subjective justification rather than empirical or statistical evidence. For the purpose of the content validity check, an initial draft of the survey was sent to a senior HR manager in a leading commercial bank in Pakistan, and to a final year $\mathrm{PhD}$ scholar majoring in HRD at Swansea University U.K. The underlying purpose behind such a check was to eradicate any vagueness regarding the important areas related to knowledge creation, as most of the research on knowledge creation focuses

Business Review: (2017) 12(2):1-21 
on western organizations and no significant standard is available for developing countries. Therefore, during the pilot study, the researcher obtained useful feedback from experts that was later used to improve and refine the survey. The researcher incorporated various changes in the initial draft based on the feedback and comments of the respondents.

\subsection{Reliability and validity in the post-hoc scale validation phase}

The reliability of the scale is associated with the one-dimensional nature of the scale Anderson and Gerbing (1991). The one-dimensional measure fits with the data reasonably well, showing low measurement error McDonald (1981). Furthermore, the one-dimensional test examines the measurement errors and eliminates weak factor loadings and also checks the adequacy of the model through the re-specified model and measures reliability. Therefore, the one-dimensional test was performed in the post-hoc scale development phase. The researcher initially specified the measurement model for each construct by processing survey data $(\mathrm{n}=346)$ in the statistical package IBM AMOS v19 using maximum likelihood estimation method.

In case of the validity of the scale in the post-hoc scale validation phase, the measurement model in the CFA was used to assess both the convergent and discriminant validities. Methodologically, the CFA measurement model was processed to test the relationship between the latent construct and measure the convergent and discriminant validities. Farrell and Rudd (2009) (p.19) highlights that "if a factor analysis is misinterpreted, and discriminant validity is not established, then measurement scales used in research may not function correctly, and conclusions made regarding relationships between constructs under investigation may be incorrect." Therefore, the validity of the scale was measured using CFA method based on two steps: i) application of CFA measurement model and; ii) assessment of convergent and discriminant validity.

The CFA measurement model is normally used when a solid theoretical foundation of the latent variable structure is available Byrne (2003). The purpose behind such a measurement model is to test the validity of the selected variables through the adequacy of the hypothesized factor structure Byrne (2005). In addition, the structural model should be based on a certain hypotheses (or a-priori theory). Therefore, based on the knowledge (or priori), a relationship between the observed variables and the underlying latent factors has been drawn based on a certain hypothetical model or hypothesis. In the case of this study, the SECI knowledge creation theory gives conceptual backings for the underlying latent variable structure. In this connection, the following research hypothesis (H1) has been developed.

H1: Knowledge creation scale developed for this study can be employed to enhance the insights of Pakistani banking organizations into their knowledge creation process.

The subsequent section summarises the detail of both reliability and validity techniques used in the post-hoc scale validation phase. 


\subsubsection{Reliability (one-dimensionality) in the post-hoc scale validation phase}

The knowledge creation measurement model includes four phases: socialization, externalization, combination, and internalization. All the four phases are measured with seven observed variables each. The one-dimensional analysis was conducted using the following two steps. In the first step, initial CFA was run with the entire construct that includes a total of 60 (i.e. 28 observed +32 unobserved and 32 exogenous +28 endogenous) variables. However, in the next step, the re-specified measurement model runs only with those items that were generated in the initial model.

Following the instructions of Byrne (2003), each of the four factors are inter-

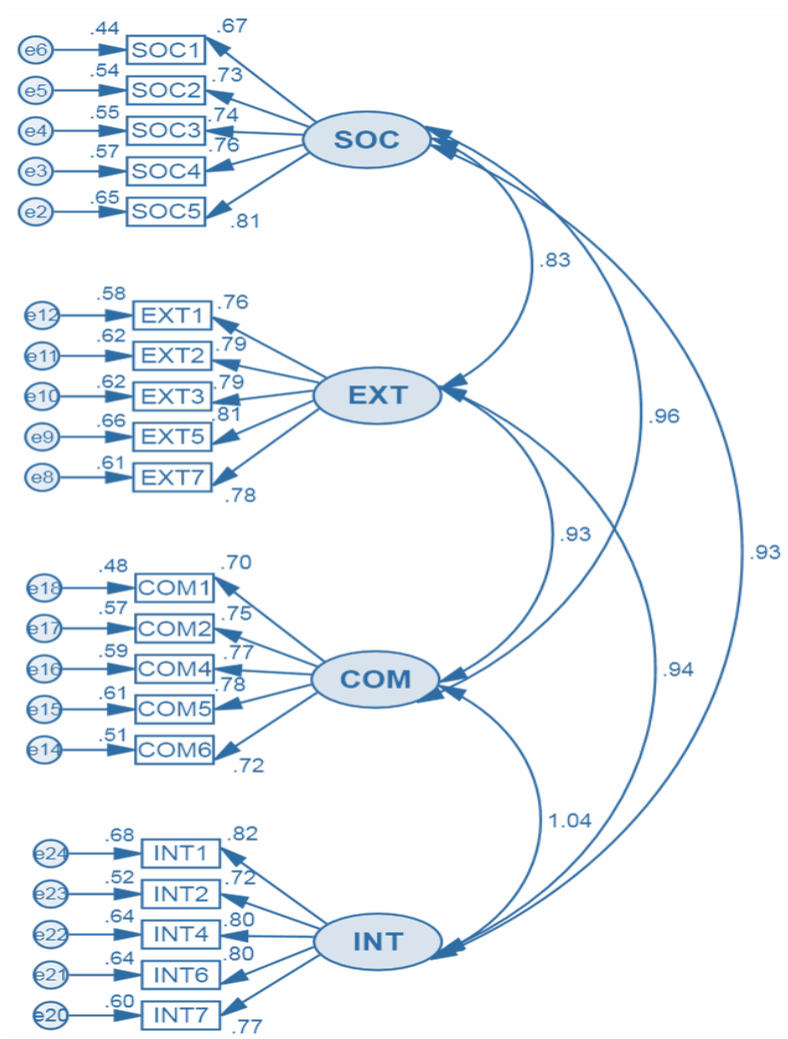

Fig. 1: AMOS path diagram of re-specified first order CFA estimates

correlated and the observed variable regressed on its respective factor. The initial findings reveal that the measurement model that includes four factors and 28 observed variables call for more re-specification to attain a model fit. For example, initial model fit estimates (i.e. $\chi 2=575.142$, $\mathrm{df}=344, \chi 2 / \mathrm{df}=1.67$, $\mathrm{CFI}=0.883, \mathrm{TLI}=0.871, \mathrm{IFI}=0.885, \mathrm{RFI}=0.731, \mathrm{NFI}=0.755$ and $\mathrm{RMSEA}$ $=0.072$ ) indicate that the initial model requires further re-specification. There-

Business Review: (2017) 12(2):1-21 
fore eight items (i.e. SOC6, SOC7, EXT4, EXT6, COM3, COM7, INT3 and INT5) were deleted due to low factor loadings and corresponding low squared multiple correlations.

For the purpose of analysis in the next stage, the re-specified measurement model runs with only those items that were generated in the initial model. Figure 1 shows the AMOS path diagram of the re-specified CFA estimates and factor loadings. As shown, AMOS path diagram of the re-specified first order CFA contains a total of 44 (i.e. 20 observed +24 unobserved) variables. In terms of adequacy, the re-specified model described the sample data fairly well. More specifically, regression weights (factor loadings) of all variables load adequately against their respective factors. All the factor loadings between 0.67 to 0.82 and all critical ratios between 7.21 to 11.01 indicated that the regression weights of all factors are statistically significant at 95 percent confidence level.

The results summarized in table 3 show the model fit results of the initial and re-specified first-order CFA. In order to examine the one-dimensionality of the knowledge creation scale, the researcher included four model fit indices such as, absolute fit indices, comparative fit indices, predictive fit indices and parsimonious fit indices. For example, the results summarized in table 3 show three absolute fit indices comprised on i) Chi-Square $(\chi 2)$; ii) Ratio of $\chi 2$ to df and; iii) Browne Cudeck Criterion. In the present model, chi-square value $(\chi 2=355.736)$ of the re-specified model as compared to chi-square value $(\chi 2$ $=575.142)$ of the initial measurement model indicates that, 44 variables $(20$ observed +24 unobserved) of SECI knowledge creation scale fit very well into the data. Likewise, ratio of chi-square to degree of freedom of the re-specified model is also included.

Harrington (2008) indicated that the chi-square value is sensitive to sample size. For that reason, ratio of chi-square to degree of freedom $(\chi 2 / \mathrm{df})$ is usually used to compensate the discrepancy in the results. The result of $\chi 2 / \mathrm{df}=2.169$ of the re-specified model also indicates the statistical significance of the model at ${ }^{*} \mathrm{p}<.000$. Additionally, the result of Browne Cudeck Criterion $(\mathrm{BCC}=$ $513.167)$ index also shows the adequacy of the factor structure of the knowledge creation measurement model in the context of Pakistani banking organizations.

However, in some situations, $\chi 2$ does not report precise valuation of a model fit or the fit statistics may not clarify the conceptual viewpoints of the model. Thus, an alternative fit statistic is typically considered to determine the precise valuation of the model. In the present model, the Root Mean Square Error of Approximation (RMSEA) is included in table 3.

Generally speaking, RMSEA is the most important model fit statistic that may be used as an alternative for precise valuation of model fit. According to Browne et al (1993), RMSEA value less than 0.06 or 0.08 with confidence interval means that the model offers a good fit. The results of a root mean square residual $(\mathrm{RMSEA}=0.095)$ also reveal the adequacy of the factor structure of the knowledge creation measurement at $95 \%$ confidence interval. The comparative fit index results summarized in table 3 also indicate that the re-specified model demonstrated a good fit in all aspects and the estimated values, for example, $\mathrm{CFI}=0.901, \mathrm{TLI}=0.885, \mathrm{IFI}=0.90, \mathrm{NFI}=0.833$ and $\mathrm{RFI}=0.806$ remained behind the threshold limit. Hence, this result is implying the unidimensionality 
Measuring the knowledge creation process...

Table 3: Comparative fit results based on initial and re-specified models

\begin{tabular}{|c|c|c|c|}
\hline Model fit Indices & $\begin{array}{l}\text { Initial } \\
\text { model fit } \\
\text { results }\end{array}$ & $\begin{array}{l}\text { Re-specified } \\
\text { model fit } \\
\text { results }\end{array}$ & Model fit threshold \\
\hline $\begin{array}{l}\text { Absolute Fit Indices } \\
\text { Chi-square } \\
\text { Degrees of freedom } \\
\text { Ratio of } \chi 2 \text { to df } \\
\text { Browne Cudeck Criterion } \\
\text { RMSEA }\end{array}$ & $\begin{array}{l}575.142 \\
344 \\
1.671 \\
806.825 \\
0.072\end{array}$ & $\begin{array}{l}355.736 \\
164 \\
2.169 \\
513.167 \\
0.095\end{array}$ & $\begin{array}{l}\text { Smaller the better } \\
\text { Smaller the better } \\
\leq 2 \text { or } 3 \\
\text { Smaller the better } \\
>.05 \text { but }<.08 \text { reasonable } \\
\text { fit }\end{array}$ \\
\hline $\begin{array}{l}\text { Comparative Fit Indices } \\
\text { Comparative Fit Index } \\
\text { TuckerLewis Index } \\
\text { Incremental Fit Index } \\
\text { Normed Fit Index } \\
\text { * Relative Fit Index }\end{array}$ & $\begin{array}{l}0.883 \\
0.871 \\
0.885 \\
0.755 \\
0.731\end{array}$ & $\begin{array}{l}0.901 \\
0.885 \\
0.902 \\
0.833 \\
0.806\end{array}$ & $\begin{array}{l}0>\text { CFI }>1 \text { for acceptance } \\
0>\text { TLI }>1 \text { for acceptance } \\
\geq 0.95 \text { for acceptance } \\
\geq 0.95 \text { for acceptance } \\
\geq 0.95 \text { for acceptance }\end{array}$ \\
\hline $\begin{array}{l}\text { Predictive Fit Indices } \\
\text { Akaike Information Crite- } \\
\text { rion } \\
\text { Expected Cross- } \\
\text { Validation Index }\end{array}$ & 755.142 & 487.736 & $\begin{array}{l}\text { Smaller the better } \\
\text { Smaller the better }\end{array}$ \\
\hline $\begin{array}{l}\text { **Parsimonious Fit In- } \\
\text { dices } \\
\text { Parsimony-Adjusted NFI } \\
\text { Parsimony-Adjusted }\end{array}$ & $\begin{array}{l}0.687 \\
0.803\end{array}$ & $\begin{array}{l}0.719 \\
0.778\end{array}$ & $\begin{array}{l}\text { Closer to } 1 \text { the better } \\
\text { Closer to } 1 \text { the better }\end{array}$ \\
\hline \multicolumn{4}{|c|}{$\begin{array}{l}\text { *Similar to CFI but can be negative, therefore, CFI better choice. } \\
\text { ** Very sensitive to model size } \\
\text { Source: Carmines and McIver (1981), Hu and Bentler (1999), Browne and } \\
\text { Cudek (1993) }\end{array}$} \\
\hline
\end{tabular}

of the factor structure.

\subsubsection{Validity of knowledge creation scale in the post-hoc scale validation phase}

The underlying purpose of the CFA model with a second-order factor (see figure 2 ) is to facilitate hypothesis testing $\mathrm{H} 1$ and to measure convergent and discriminate validity. The factor indicators of the first-order factors SOC, EXT, COM and INT are continuous and indicate the relationship between the latent construct in the model. The first-order factors are indicators of the second-order factor $\mathrm{KC}$.

In this model, $\mathrm{SOC}$ is measured by $\mathrm{SOC} 1, \mathrm{SOC} 2, \mathrm{SOC} 3, \mathrm{SOC} 4$ and SOC5;

Business Review: (2017) 12(2):1-21 
EXT is measured by EXT1, EXT2, EXT3, EXT5 and EXT7; COM is measured by COM1, COM2, COM4, COM5 and COM6 and INT is measured by INT1, INT2, INT4, INT6 and INT7. However, the second-order factor KC is measured by SOC, EXT, COM and INT. The results presented in table 4 show the knowledge creation measurement model. For example, the model fit result of the chi-square $(\chi 2=490.414)$ indicates that 44 variables $(20$ observed +24 unobserved) of SECI knowledge creation construct fit the data reasonably well.

The ratio of chi-square to degree of freedom $(\chi 2 / \mathrm{df}=490.414 / 170=2.88)$ indicate that the second order CFA model is statistically significant at $\mathrm{p}<$ .000. Alternatively, the results of other absolute fit indices, for example, BCC $=985.827, \mathrm{BIC}=108.422, \mathrm{CAIC}=1125.422$ and $\mathrm{RMR}=0.482$ also provided a marginally acceptable fit for the knowledge creation measurement model. The comparative fit statistics of second-order CFA demonstrated a good fit in all aspects. All the estimated values, for example, NFI $=0.881$, IFI $=0.932$, TLI $=0.984$, CFI $=0.928$ and $\mathrm{RFI}=0.832$ remained behind the threshold limit.

The three parsimony correction statistics, for example, PNFI $=0.520$ and $\mathrm{PCFI}=0.562$ also demonstrated a good fit to the data. Another, two predictive fit indices results i.e. AIC $=970.414$ and $\mathrm{ECVI}=7.465$ also demonstrated a much better fit according to the benchmark limit. Three alternative fit results, $\mathrm{GFI}=0.621, \mathrm{AGFI}=0.532$ and $\mathrm{RMSEA}=0.080$ also indicated that the hypothesized model fits the data well at $90 \%$ confidence interval.

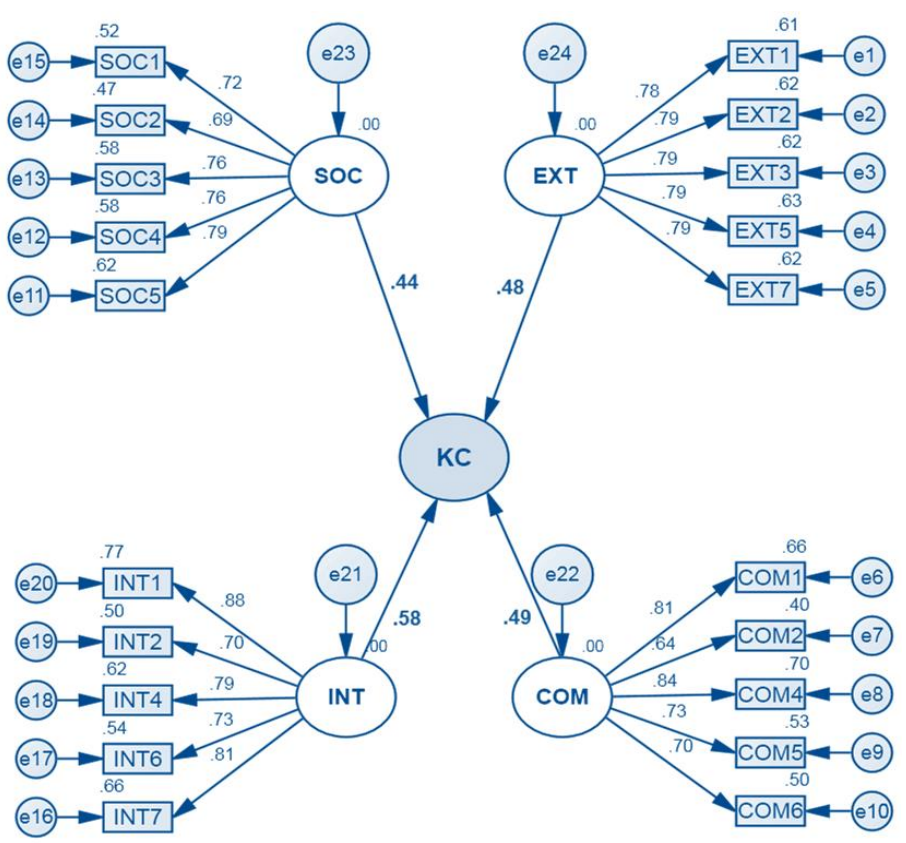

Fig. 2: AMOS path diagram second order CFA estimates 
In general, model fit results of second-order CFA model provide a reasonable fit to the data in this study. In other words, all the model fit values presented in table 4 supported the usefulness of the four domains of the knowledge creation theory and items reflect the knowledge creation process in the Pakistani banking organizations. For example, the standardized estimates of this model can be used to evaluate the "relative contribution of each predictor variable" Arbuckle (1995). Following the suggested threshold limit of Kline (2015) the path coefficients $\geq 0.10$ represent a small effect, path coefficients $\geq 0.30$ represent a medium effect, and path coefficients $\geq 0.50$ represent a large effect; the path coefficients of the 20 items and four knowledge creation domains of knowledge creation scale confirmed that the measurement model adequately described the sample data in the Pakistani banking organizations.

For measuring convergent validity of the construct, the researcher utilized the frequently used method typically known as the average variance extracted (AVE). The AVE measures the degree of variance in the indicators accounted for by the latent construct Hair et al (2010). According to Fornell and Larcker (1981), the AVE is a more conservative test of convergent validity as it measures the degree of variance determined by the construct relative to the degree of variance determined by the measurement error.

AVE can be judged to be adequate when the measured value equals or exceeds 0.50 . As shown in table 5 , the AVE value for SOC is 0.555 . It means that the $55.5 \%$ of the variance is explained by the SOC construct, and $44.5 \%$ due to measurement error. According to Fornell and Larcker (1981), constructs should exhibit estimates of .50 or greater. In case of four dimensions of the knowledge creation scale, the AVE values (i.e. $\mathrm{SOC}=0.555, \mathrm{EXT}=0.620, \mathrm{COM}=0.557$ and INT $=0.616$ ) demonstrate an acceptable fit according to the benchmark limit.

It validates that the variance captured by the factor is greater than the variance due to measurement error. Thus, variance extracted estimates meet this minimum threshold, so the validity of the latent constructs, as well as the associated constructs, is acceptable. Table 5 also contains the composite reliability (CR) results of the four latent factors included in the model. It found that, all the $\mathrm{CR}$ values meet that minimum acceptable level of 0.60 as suggested by Fornell and Larcker (1981).

In order to assess the discriminant validity, AVE values were utilized. Fornell and Larcker (1981) indicated that, discriminant validity can support the construct when AVE estimates are greater than the square of the inter-factor correlation. For instance, the correlation between SOC and EXT is 0.605 and the squared correlation (i.e. $0.605^{2}$ ) is 0.366 . In the case of knowledge creation construct, AVE for SOC and EXT is 0.557 and 0.620 respectively. As both values $0.557>0.366$ and $0.620>0.366$ they support discriminant validity within the model. 
Table 4: Model fit results of second order CFA model

\begin{tabular}{|c|c|c|}
\hline Model Fit Indices & $\begin{array}{l}\text { Second Order CFA } \\
\text { Model Fit Results }\end{array}$ & Model Fit threshold limits \\
\hline \multicolumn{3}{|l|}{ Absolute Fit Indices } \\
\hline Chi-square & 490.414 & Smaller the better \\
\hline Ratio of $\chi 2$ to $\mathrm{df}$ & 2.88 & $\leq 2$ or 3 \\
\hline Browne Cudeck Criterion & 985.827 & $\overline{\text { Smaller the better }}$ \\
\hline $\begin{array}{l}\text { Bayes Information Crite- } \\
\text { rion }\end{array}$ & 1085.422 & Smaller the better \\
\hline Consistent AIC & 1125.422 & Smaller the better \\
\hline $\begin{array}{lll}\text { Root } & \text { Mean } & \text { Residual } \\
\text { RMR } & & \\
\end{array}$ & 0.482 & 0 indicates perfect fit \\
\hline \multicolumn{3}{|l|}{ Comparative Fit Indices } \\
\hline Normed Fit Index & 0.881 & $\geq 0.95$ for acceptance \\
\hline Incremental Fit Index & 0.932 & $\geq 0.95$ for acceptance \\
\hline TuckerLewis Index & 0.984 & $\overline{0}>\mathrm{TLI}>1$ for acceptance \\
\hline Comparative Fit Index & 0.928 & $0>\mathrm{CFI}>1$ for acceptance \\
\hline Relative Non-Centrality & 0.832 & $\geq 0.95$ for acceptance \\
\hline \multicolumn{3}{|l|}{ Fit Index } \\
\hline \multicolumn{3}{|l|}{ Predictive Fit Indices } \\
\hline $\begin{array}{l}\text { Akaike Information Crite- } \\
\text { rion }\end{array}$ & 970.414 & Smaller the better \\
\hline \multicolumn{3}{|l|}{ Validation Index } \\
\hline \multicolumn{3}{|l|}{ Parsimonious Fit Indices } \\
\hline Parsimony-Adjusted NFI & 0.52 & Very sensitive to model size \\
\hline Parsimony-Adjusted CFI & 0.562 & Very sensitive to model size \\
\hline \multicolumn{3}{|l|}{ Alternative Fit } \\
\hline Goodness of Fit & 0.621 & $\begin{array}{l}\geq 0.95 \text { not generally recom- } \\
\text { mended }\end{array}$ \\
\hline Adjusted GFI & 0.532 & $\begin{array}{l}\geq 0.95 \text { performances poor in } \\
\text { simulation studies }\end{array}$ \\
\hline RMSEA & 0.08 & $\leq 0.06$ to 0.08 with confidence interval \\
\hline \multicolumn{3}{|c|}{$\begin{array}{l}\text { Source: Carmines and McIver (1981), Hu and Bentler (1999), Browne and Cudek } \\
\text { (1993) } \\
\text { Similar to CFI but can be negative, therefore CFI better choice }\end{array}$} \\
\hline
\end{tabular}




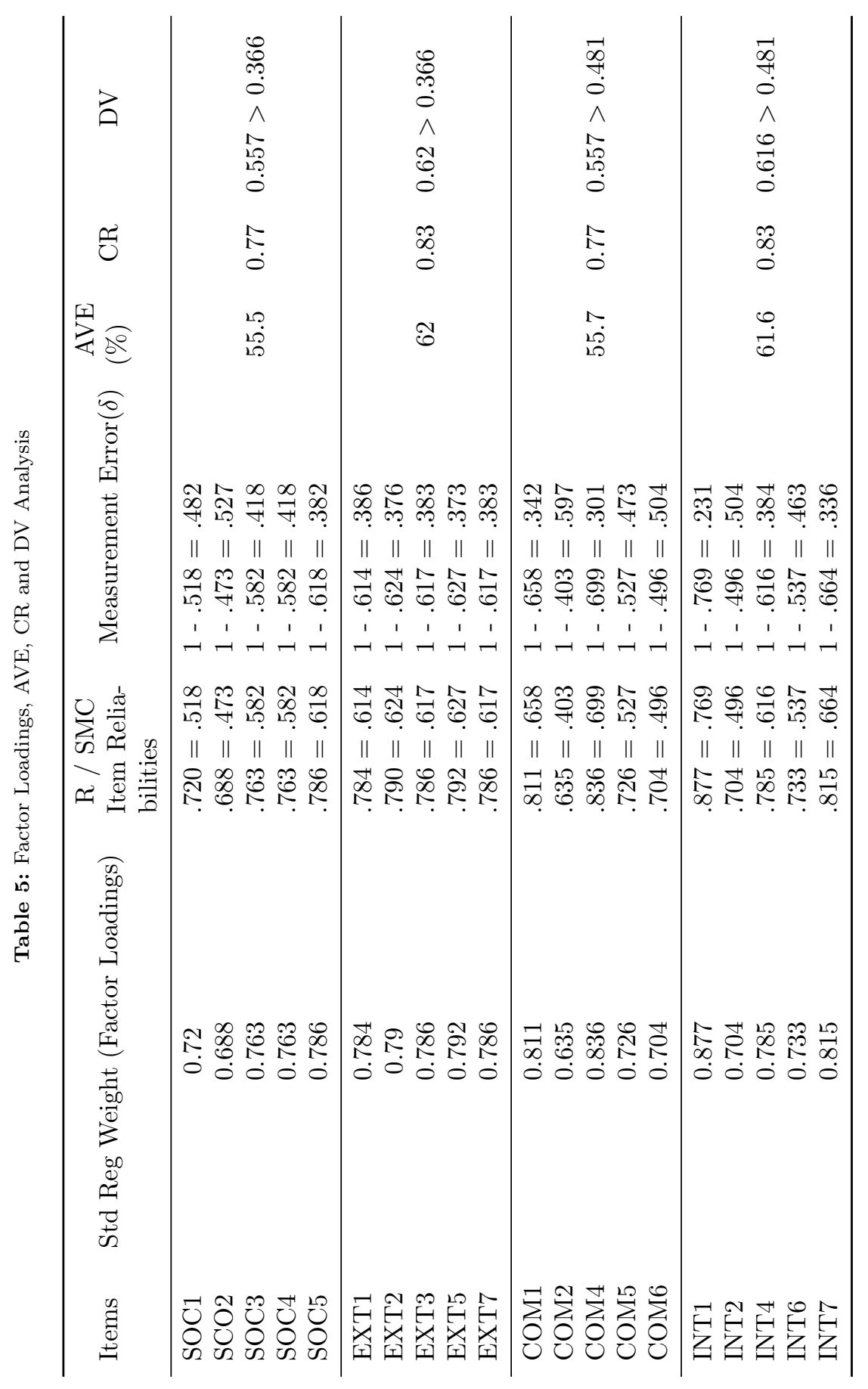

Business Review: (2017) 12(2):1-21 


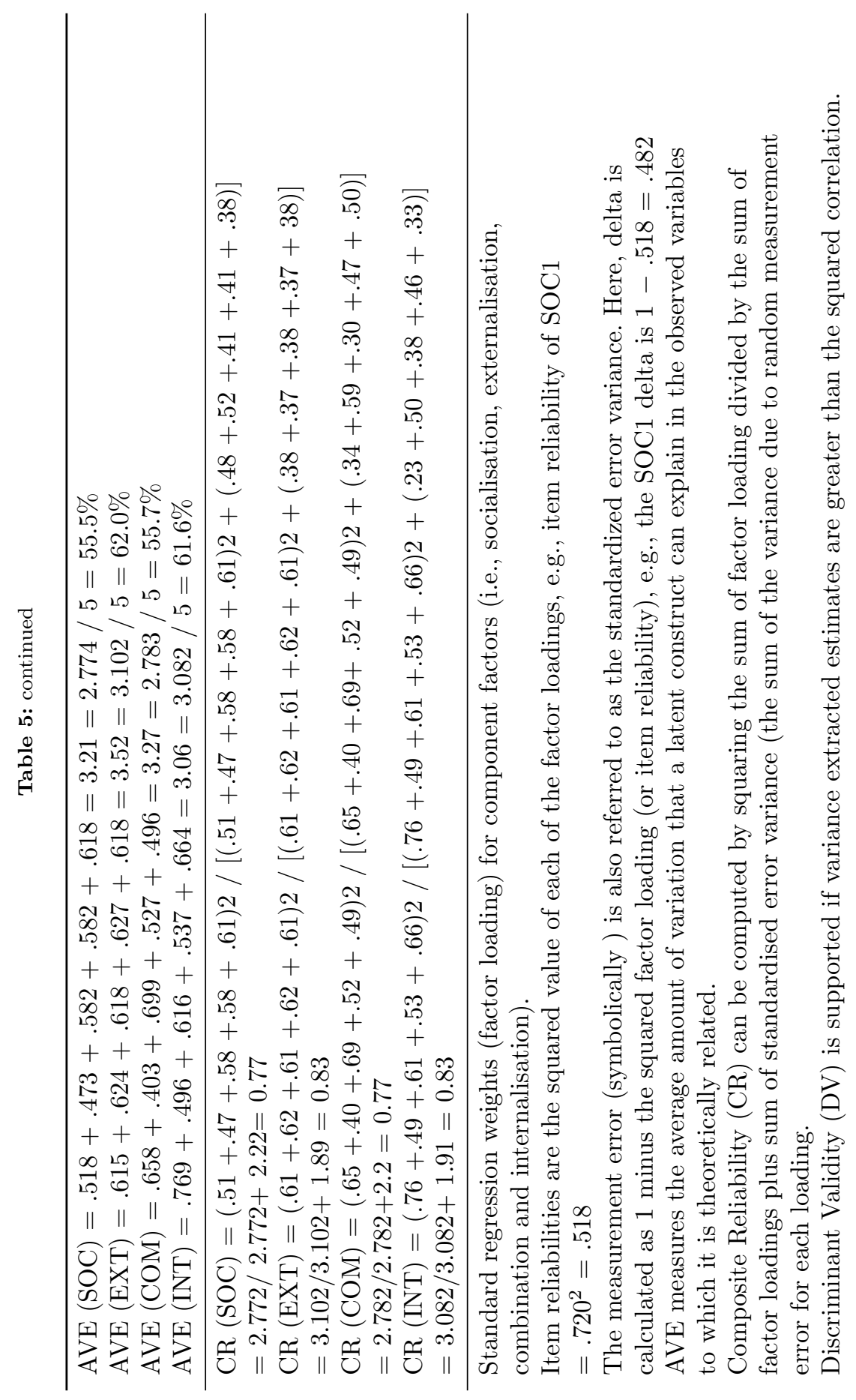




\section{Discussion}

The theory testing results through the adequacy of the hypothesized factor structure using a confirmatory factor analysis confirmed the presence of knowledge creation process in Pakistani banks. According to the findings, the SECI process (i.e. socialization, externalization, combination, and internalization) performed an effective role in the knowledge creation within Pakistani banks. These findings were in agreement with the literature suggesting that the organizational knowledge creation occurs when all knowledge creation modes are organizationally managed to achieve a continual cycle Nonaka and Takeuchi (1995).

The validation of the SECI theory in Pakistani banks indicated that knowledge creation through knowledge conversion modes is not only a Japanese phenomenon, but it can also be applicable in the developing countries. These findings received support from Von Krogh et al (2000) Glisby and Holden (2003) Haag et al (2009) Andreeva and Ikhilchik (2011) which suggest that the SECI model is universally applicable if the right context of knowledge sharing is provided. This finding helps the researcher in understanding how the knowledge creation process is taking place in Pakistani banks through the four knowledge creation modes. For example, the empirical findings indicated socialization as a key antecedent for transfer of tacit knowledge in Pakistani banks.

Bank employees were involved in socialization during face to face interaction, on-the-job and off-the-job trainings. The transfer of tacit knowledge through social interaction in Pakistani banks also confirmed the characteristics of a collectivist society based on strong, cohesive groups and sound moral provisos (Hofstede and Hofstede, 2005). This finding gets support from Rodrigues et al (2006) that socialization can be achieved with conversation between people when they tend to share ideas and experiences. It implies that the workplace collectivism is a powerful enabler of knowledge sharing and exchange as it encourages cooperation and teamwork that could be significant in the knowledge creation process. This finding also supported the conviction that people are propelled through a strong interaction in which collectivism reinforces the culture of trust and loyalty and encourages socialization in the organization Wang et al (2011).

The process for making tacit knowledge explicit is externalization. In the organizational context, the externalization process can be achieved through facilitating creative and constructive conversations among group members and teams. The findings of this study indicate that the tacit knowledge of staff, colleagues, and group members was converted into explicit knowledge during face to face and online conversations in Pakistani banks. The confirmatory factor analysis showed that the respondents usually were able to explain their thoughts with examples when others cannot understand. Also, knowledge is made explicit through transcribing unorganized thoughts into concrete ideas.

The findings of this study confirmed that people transcribe intangible thoughts into concrete ideas during face to face dialogue with other members. Employees also transform tacit knowledge into explicit knowledge by describing technical or practical terminologies with conversational language, helping others to clarify their points or ideas. According to the findings, employees facilitate creative and constructive conversations among group members in which they help others 
express what they have in mind and continue what they are saying. These findings are in agreement with Paz Salmador and Bueno (2007) who suggested that externalization can be achieved when people seek and receive assistance from each other regarding technical terminologies and professional language used in routine communication within the organization.

In terms of the combination process, the present Pakistani banking system allows employees to combine different types of explicit knowledge into a clearer explicit knowledge whilst performing the job. For this, the knowledge management system in Pakistani banks currently uses a method to smooth the process of collecting and updating new information and organizing ambiguous concepts into structure. Factor loading during CFA indicates that employees collect new information and make connections between new and old knowledge. The combination of knowledge is also attained in different workplace engagements, especially when employees are developing criteria to determine the value of new concepts.

However, knowledge combination may well be supported in a mutual environment. Group members tend to organize ideas and make conclusions, facilitate group discussions; apply experiences to help solve problems; take notes and make a summary of every meeting, event or discussion; and organize others thoughts and opinions in their mind Nonaka and Konno (1998). It also confirmed that employees organize ideas and make conclusion to facilitate discussion in which they get help from their previous problem solving experience. These findings are same as those of Rice and Rice (2005) Smith et al (2005) and Schulze and Hoegl (2008). They agreed that when individuals collect and reformulate relevant information and combine it in different activities, they create new knowledge.

The internalization process in knowledge creation facilitates comparing and contrasting existing and new ideas (or concepts) with personal experience in order to understand its meaning. It helps personal understanding by rectifying personal mistakes, and making concepts more eloquent and applicable. In the case of this study, respondents are in agreement that they tend to compare new ideas or concepts with experience to help comprehend the meaning.

In knowledge internalization, knowledge becomes valuable when it is internalized by individuals from tacit knowledge bases and shared mental models Nonaka et al (2000). Bank employees agreed that they combine existing and new concepts in a meaningful way in which they give others time to think about what they just discussed when communicating. The confirmatory factor analysis findings also validated that internalization activities helped Pakistani banks to internalize explicit knowledge into tacit knowledge during the knowledge creation process. It also supported Freeze and Kulkarni (2005) that the decision on knowledge acquisition and transfer originates from within the capabilities provided by a firm's human capital.

The validation of the scale provides an opportunity for banking practitioners to monitor the knowledge creation process within a bank. It will be even more beneficial to see the correlation of the knowledge creation process with other indices such as employee performance and organizational profitability. 


\section{Limitations}

In some cases, unseen methodological issues create major limitations to validity. A confirmatory factor analysis (CFA) and the non-response bias estimates between paper and electronic survey responses are thus used to mitigate the impact of major limitations to validation. For this, numerous types of measures lend themselves particularly well to validity generalization Schmidt and Hunter (1998). Translation validity and criterion related validity provide a validity generalization of the statistical findings.

In spite of the limitations of the final research process including lack of representativeness and validity of statistical findings, the evidence of both convergent and discriminate validity categorically supports that the predictor variable in one specific setting can be generalized to another similar set of situations. For example, translation validity (i.e. face validity and content validity) provides a thorough definition of the construct in terms of method and design. In contrast, criterion related validity (i.e. convergent validity and discriminate validity) is a more relational approach to construct validity in relation to method and design based upon theory of the construct in a more predictable way.

\section{Future direction}

For this study, a total of 346 cases were drawn from 50 branches of commercial banks in Karachi. Since, additional work is needed, more cases may be required from more than three banks for more credible analysis. Also, this study considered the banking sector only. This implies that some of the results may not apply in other settings. Consequently, it would be interesting to conduct a similar research; for example, in another service sector organization or other related organizations. Nevertheless, the closeness of the findings to general, theoretical predictions may be noteworthy.

For applying the confirmatory factor analysis (CFA) and structural equation modelling (SEM) using a maximum likelihood (ML) method, the sample size must be valid. Similarly, all the conditions must be satisfied before running the CFA and SEM. However, it would be pertinent to conduct the CFA and SEM with a larger sample size for more credible results in any future research.

In terms of literary contribution, this study is an attempt to provide a comprehensive validation framework of the knowledge creation construct. However, it would be highly recommended to identify how these validated constructs act and react to other phenomenon in the industry, in the country and other countries. Indeed, it would be interesting to see the comparison of how these CFAvalidated constructs act in Pakistan versus India, or other developing countries alongside Japan or USA, etc.

\section{References}

Ahire SL, Devaraj S (2001) An empirical comparison of statistical construct validation approaches. IEEE Transactions on Engineering Management 48(3):319-329

Business Review: (2017) 12(2):1-21 
Akhtar MH (2001) Multinational banking in pakistan. Global Business Review 2(2):235-242 Albright JJ, Park HM (2009) Confirmatory factor analysis using amos, lisrel, mplus, sas/stat calis

Anderson JC, Gerbing DW (1991) Predicting the performance of measures in a confirmatory factor analysis with a pretest assessment of their substantive validities. Journal of Applied Psychology 76(5):732

Andreeva T, Ikhilchik I (2011) Applicability of the seci model of knowledge creation in russian cultural context: theoretical analysis. Knowledge and Process Management 18(1):56-66

Arbuckle JL (1995) Amos 16.0 users guide. PA: Amos Development Corporation

Bagozzi RP, Yi Y (1988) On the evaluation of structural equation models. Journal of the academy of marketing science 16(1):74-94

Bentler PM (1995) EQS structural equations program manual. Multivariate Software

Bhatti KK, Qureshi TM (2007) Impact of employee participation on job satisfaction, employee commitment and employee productivity. International Review of Business Research Papers $3(2): 54-68$

Brown TA (2014) Confirmatory factor analysis for applied research. Guilford Publications

Browne MW, Cudeck R, et al (1993) Alternative ways of assessing model fit. Sage focus editions 154:136-136

Burnette JL, Williams LJ (2005) Structural equation modeling (sem): An introduction to basic techniques and advanced issues. Research in organizations: Foundations and methods of inquiry pp $143-160$

Byosiere P, Luethge D (2004) Realizing vision through envisioning reality: Strategic leadership in building knowledge spheres. Leading in Turbulent Times Managing in the New World of Work, RJ Burke and C Cooper (eds) Malden, MA: Blackwell Publishing, pp 243À258

Byrne BM (2003) Testing for equivalent self-concept measurement across culture: Issues, caveats, and application. International advances in self research 1:291-314

Byrne BM (2005) Factor analytic models: Viewing the structure of an assessment instrument from three perspectives. Journal of personality assessment 85(1):17-32

Earl M (2001) Knowledge management strategies: Toward a taxonomy. Journal of management information systems 18(1):215-233

Farrell AM, Rudd J (2009) Factor analysis and discriminant validity: A brief review of some practical issues. Anzmac

Fornell C, Larcker DF (1981) Evaluating structural equation models with unobservable variables and measurement error. Journal of marketing research pp 39-50

Freeze R, Kulkarni U (2005) Knowledge management capability assessment: Validating a knowledge assets measurement instrument. In: System Sciences, 2005. HICSS'05. Proceedings of the 38th Annual Hawaii International Conference on, IEEE, pp 251a-251a

Glisby M, Holden N (2003) Contextual constraints in knowledge management theory: the cultural embeddedness of nonaka's knowledge-creating company. Knowledge and Process management 10(1):29-36

Haag M, Duan Y, Mathews B (2009) The impact of culture on the application of the seci model. Cultural Implications of Knowledge Sharing, Management and Transfer: Identifying Competitive Advantage: Identifying Competitive Advantage p 26

Hair JF, Black WC, Babin BJ (2010) Re anderson multivariate data analysis: A global perspective

Harrington D (2008) Confirmatory factor analysis: Oxford university press

Hashim NH, Murphy J, Law R (2007) A review of hospitality website design frameworks. Information and communication technologies in tourism 2007 pp 219-230

Hatcher L (2005) A step-by-step approach to using the SAS system for factor analysis and structural equation modeling. SAS Institute Cary, NC

Hinkin TR (2005) Scale development principles and practices. Research in organizations: Foundations and methods of inquiry pp 161-179

Jamal A, Naser K (2003) Factors influencing customer satisfaction in the retail banking sector in pakistan. International Journal of Commerce and Management 13(2):29-53

Jöreskog KG, Sörbom D (1996) LISREL 8: User's reference guide. Scientific Software International

Kao SC, Wu C, Su PC (2011) Which mode is better for knowledge creation? Management Decision 49(7):1037-1060 
Khilji SE (2003) To adapt or not to adapt' exploring the role of national culture in hrm-a study of pakistan. International Journal of Cross Cultural Management 3(1):109-132

Khilji SE (2004) Whither tradition? evidence of generational differences in hr satisfaction from pakistan. International Journal of Cross Cultural Management 4(2):141-156

Kline RB (2015) Principles and practice of structural equation modeling. Guilford publications

Maier R, Remus U (2003) Implementing process-oriented knowledge management strategies. Journal of knowledge management 7(4):62-74

McDonald RP (1981) The dimensionality of tests and items. British Journal of mathematical and statistical Psychology 34(1):100-117

Mirza S (1995) Privatisation in Pakistan. Ferozsons

Nonaka I (1994) A dynamic theory of organizational knowledge creation. Organization science $5(1): 14-37$

Nonaka I, Konno N (1998) The concept of" ba": Building a foundation for knowledge creation. California management review 40(3):40-54

Nonaka I, Takeuchi H (1995) The knowledge-creating company: How Japanese companies create the dynamics of innovation. Oxford university press

Nonaka I, Toyama R, Konno N (2000) Seci, ba and leadership: a unified model of dynamic knowledge creation. Long range planning 33(1):5-34

Nonaka I, Konno N, Toyama R (2001) Emergence of ba. Knowledge emergence: Social, technical, and evolutionary dimensions of knowledge creation 1:13-29

Nunnally J (2010) Psychometric theory 3e: Tata mcgraw-hill education

Paz Salmador M, Bueno E (2007) Knowledge creation in strategy-making: Implications for theory and practice. European Journal of Innovation Management 10(3):367-390

Rai RK (2011) Knowledge management and organizational culture: a theoretical integrative framework. Journal of Knowledge Management 15(5):779-801

Rice JL, Rice BS (2005) The applicability of the seci model to multi-organisational endeavours: an integrative review. International Journal of Organisational Behaviour 9(8):671-682

Rodrigues L, Gayathri R, Rao S (2006) Empirical study based evaluation of km models in the it sectors: Implications for quality outcomes. Journal of Knowledge Management Practice $7(3)$

Schmidt FL, Hunter JE (1998) The validity and utility of selection methods in personnel psychology: Practical and theoretical implications of 85 years of research findings. Psychological bulletin 124(2):262

Schulze A, Hoegl M (2008) Organizational knowledge creation and the generation of new product ideas: A behavioral approach. Research policy 37(10):1742-1750

Shih KH, Chang CJ, Lin B (2010) Assessing knowledge creation and intellectual capital in banking industry. Journal of intellectual capital 11(1):74-89

Smith KG, Collins CJ, Clark KD (2005) Existing knowledge, knowledge creation capability, and the rate of new product introduction in high-technology firms. Academy of management journal 48(2):346-357

Song J, Uhm D, Won Yoon S (2011) Organizational knowledge creation practice: Comprehensive and systematic processes for scale development. Leadership \& Organization Development Journal 32(3):243-259

Sureshchandar G, Rajendran C, Anantharaman R (2002) Determinants of customer-perceived service quality: a confirmatory factor analysis approach. Journal of services Marketing 16(1):9-34

Vencatachellum I, Jeetah V (2008) The state of knowledge management among the commercial banks in mauritius. In: 9th International Conferences on HRD Research and Practice across Europe

Von Krogh G, Ichijo K, Nonaka I (2000) Enabling knowledge creation: How to unlock the mystery of tacit knowledge and release the power of innovation. Oxford University Press on Demand

Wang D, Su Z, Yang D (2011) Organizational culture and knowledge creation capability. Journal of knowledge management 15(3):363-373

Winter G (2000) A comparative discussion of the notion of'validity'in qualitative and quantitative research. The qualitative report 4(3):1-14

Yang B (2005) Factor analysis methods. Research in organizations: Foundations and methods of inquiry pp 181-199

Business Review: (2017) 12(2):1-21 